\title{
Luminescence Properties of Mesoporous Silica Nanoparticles Encapsulating Different Europium Complexes: Application for Biolabelling
}

\author{
S. Lechevallier, ${ }^{1}$ J. Jorge, ${ }^{2}$ R. M. Silveira, ${ }^{2}$ N. Ratel-Ramond, ${ }^{1}$ D. Neumeyer, ${ }^{1}$ \\ M. J. Menu, ${ }^{3}$ M. Gressier, ${ }^{3}$ A. L. Marçal, ${ }^{4}$ A. L. Rocha, ${ }^{4}$ M. A. U. Martines, ${ }^{2}$ \\ E. Magdeleine, ${ }^{5}$ J. Dexpert-Ghys, ${ }^{1}$ and M. Verelst ${ }^{1}$ \\ ${ }^{1}$ Centre d'Elaboration de Matériaux et d'Etudes Structurales, Université de Toulouse, 29 rue Jeanne Marvig, BP 94347, \\ 31055 Toulouse Cedex 4, France \\ ${ }^{2}$ CCET, Universidade Federal de Mato Grosso do Sul, Campo Grande, MS, Brazil \\ ${ }^{3}$ Centre Interuniversitaire de Recherche et d'Ingénierie des Matériaux, UPS-CNRS 5085, Université de Toulouse, \\ 118 route de Narbonne, 31062 Toulouse Cedex 9, France \\ ${ }^{4}$ Universidade De Franca, Franca, SP, Brazil \\ ${ }^{5}$ ICELLTIS, Prologue 1, 815 La Pyrénéenne, 31670 Labège, France
}

Correspondence should be addressed to S. Lechevallier; severine.lechevallier@cemes.fr

Received 5 April 2013; Accepted 25 June 2013

Academic Editor: John Zhanhu Guo

Copyright (C) 2013 S. Lechevallier et al. This is an open access article distributed under the Creative Commons Attribution License, which permits unrestricted use, distribution, and reproduction in any medium, provided the original work is properly cited.

In this work we have synthesized and characterized new hybrid nanoplatforms for luminescent biolabeling based on the concept of $\mathrm{Eu}^{3+}$ complexes encapsulation in mesoporous silica nanoparticles $(\approx 100 \mathrm{~nm})$. Eu complexes have been selected on the basis of their capability to be excited at $365 \mathrm{~nm}$ which is a currently available wavelength, on routine epifluorescence microscope. For Eu complexes encapsulation, two different routes have been used: the first route consists in grafting the transition metal complex into the silica wall surface. The second way deals with impregnation of the mesoporous silica NPs with the Eu complex. Using the second route, a silica shell coating is realized, to prevent any dye release, and the best result has been obtained using Eu-BHHCT complex. However, the best solution appears to be the grafting of Eu(TTA) ${ }_{3}$-Phen-Si to mesoporous silica NPs. For this hybrid, $\mathrm{mSiO}_{2}-\mathrm{Eu}(\mathrm{TTA})_{3}(\mathrm{Phen}-\mathrm{Si})$ full characterization of the nanoplatforms is also presented.

\section{Introduction}

Recent breakthroughs in the synthesis of mesoporous silica materials with the control of the particle size, the morphology, and the porosity, along with their chemical stability, have made silica matrices highly attractive as the structural basis for a wide variety of nanotechnological applications such as adsorption, catalysis, sensing, and separation [17]. In addition, some authors have highlighted that surfacefunctionalized mesoporous silica nanoparticle (MSN) materials can be readily internalized by animal and plant cells without posing any cytotoxicity issue in vitro $[8,9]$. These new developments offer the possibility of designing a new generation of drug/gene delivery systems and biosensors for intracellular controlled release applications.

Another possible application consists in encapsulating a luminescent dye in plain or mesoporous silica nanoparticles for optical biolabeling [10-12]. For this goal, the dye molecule must be perfectly trapped inside the mesoporous matrix in order to prevent the leaching and bleaching effects. Many dye molecules can be encapsulated inside mesoporous NPs; however, we think that lanthanide complexes as $\mathrm{Eu}^{3+}$ or $\mathrm{Tb}^{3+}$ have the strong competitive advantage (versus commercial 
organic probes) to allow the time delayed measurement for complete extinction of the biological self-fluorescence during the measurement [13]. Moreover, encapsulated lanthanide chelates are not, or weakly, subjected to photobleaching or photobleaking, they are chemically very stable and non-toxic. All these factors constitute major advances, as it has been well demonstrated by Dr. Jin and his team [14].

However, for most luminescent $\mathrm{Eu}^{3+}$ and $\mathrm{Tb}^{3+}$ complexes, one of the major drawbacks is that optical excitation window is limited to the far-UV $(<330 \mathrm{~nm})$ range. Far-UV excitation is often problematic in biology because it causes damages to the cellular matter. Excitation below $330 \mathrm{~nm}$ involves poor transmission in most optics, is bulky, expensive, and has limited light sources. Most of commercial flow cytometers and microscopes are not used at these wavelengths [14-16].

Several longer-wavelength-sensitized $\mathrm{Eu}^{3+}$ complexes have been developed in recent years [17-22] and used as biolabels for time-resolved luminescence bioimaging applications. Their properties have been illustrated, for example, by the highly specific and sensitive imaging of an environmental pathogen, that is, Giardia lamblia [23], and by the use of bioconjugated silica nanoparticles embedding an europium complex to mark cancerous cells [24]. However for our knowledge, encapsulation of such complexes inside mesoporous nanoparticles has not been done systematically. The main advantage of mesoporous NPs is their high loading capability compare to plain $\mathrm{SiO}_{2} \mathrm{NPs}$, which can potentially lead to brighter probes. Consequently, the main goal of this work is to encapsulate these new long wavelength-sensitized $\mathrm{Eu}^{3+}$ complexes and to characterize the derived new nanohybrids, for cellular labeling, using light excitation in the NUV range $(355-365 \mathrm{~nm}$ ) given by laser (or Hg lamp) sources available on flow cytometer or fluorescent microscope. To reach this goal we have used two different approaches. The first route consists in grafting transition metal complexes into the silica wall surface by using a bifunctional ligand which can chelate the metal on one side and react with the silica wall on the other side (samples named as $\mathrm{mSiO}_{2}$ $\mathrm{XXX}$ in the following). The second way is easier and consists in impregnating the mesoporous silica NPs with the $\mathrm{Eu}^{3+}$ complex and then to elaborate a silica shell coating which will prevent any dye release (samples named as $\mathrm{mSiO}_{2} @ \mathrm{XXX}$ in the following).

\section{Experimental Section}

2.1. Reagents and Materials. Most reagents were purchased from Sigma-Aldrich. N,N'-Dimethylformamide (DMF), hexane, chloroform, and ethanol were of analytical grade and used without any further purification. $\mathrm{Eu}\left(\mathrm{NO}_{3}\right)_{3}$ was aqueous stock solution from Rhodia.

\subsection{Chemical Synthesis}

2.2.1. Synthesis of Mesoporous Silica Nanoparticles $\left(\mathrm{mSiO}_{2}\right)$. Typically, $0.2821 \mathrm{~g}$ of $\mathrm{NaOH}$ (PRS Panreac) and $1.048 \mathrm{~g}$ of cetyltrimethylammonium bromide $(\mathrm{CTAB})$ were mixed with $480 \mathrm{~mL}$ of distilled water. After this, the mixture was kept under constant stirring, and the temperature was increased up to $80^{\circ} \mathrm{C}$. $5 \mathrm{~mL}$ of tetraethyl orthosilicate (TEOS) was added as the silica precursor, dropwise, slowly (in $20 \mathrm{~min}$ approximately). The mixture was kept at $80^{\circ} \mathrm{C}$ under vigorous stirring for $20 \mathrm{~h}$. The obtained precipitate was centrifuged and washed with water. The sedimented product was rapidly dried in an oven at $60^{\circ} \mathrm{C}$ and then treated at $500^{\circ} \mathrm{C}$ for $5 \mathrm{~h}$ (increase $1^{\circ} \mathrm{C} / \mathrm{min}$ ), in order to decompose all the surfactants. The final weight of the obtained silica was approximately $1.0 \mathrm{~g}$.

2.2.2. Synthesis of $\mathrm{Eu}(\mathrm{TTA})_{3}$ (Phen-Si) and Grafting in $\mathrm{mSiO}_{2}$. $\mathrm{Eu}(\mathrm{TTA})_{3}(\mathrm{Phen}-\mathrm{Si})$ complex was prepared via a two-step process as shown in Figure 1.

(a) Synthesis of Ligand Phen-Si. The ligand was prepared according to the procedures described by $\mathrm{Li}$ et al. $[25,26]$. Typically, 5-amino-1,10-phenanthroline (4.1 mmol, $800.4 \mathrm{mg})$ was dissolved in $\mathrm{CH}_{3} \mathrm{Cl}(75 \mathrm{~mL})$, and 3-(triethoxysilyl)propyl isocyanate $(4.5 \mathrm{mmol}, 1.11 \mathrm{~mL})$ was added to the solution. The mixture was then reduced to a volume of $5 \mathrm{~mL}$ and refluxed at $65^{\circ} \mathrm{C}$ under Ar overnight. Cold hexane was then added to precipitate the powder. This powder was collected by centrifugation, washed with hexane, and dried under vacuum overnight.

Elemental analysis for $\mathrm{C}_{22} \mathrm{H}_{30} \mathrm{~N}_{4} \mathrm{O}_{4} \mathrm{Si}, \%$, found (calcd.): C 52.8 (57.4); H 5.7 (6.22); N 12.1 (13.4). ${ }^{1} \mathrm{H}$ NMR $\left(300.13 \mathrm{MHz} ; \mathrm{CDCl}_{3}, \delta_{\mathrm{H}}\right.$ ppm) $0.63\left(2 \mathrm{H}, \mathrm{m}, \mathrm{CH}_{2}, 14-\mathrm{H}\right), 1.10$ $\left(9 \mathrm{H}, \mathrm{t}, J_{\mathrm{AB}} 7, \mathrm{CH}_{3}, 16-\mathrm{H}\right), 1.68\left(2 \mathrm{H}, \mathrm{m}, \mathrm{CH}_{2}, 13-\mathrm{H}\right), 3.34(2 \mathrm{H}$, $\left.\mathrm{m}, \mathrm{CH}_{2}, 12-\mathrm{H}\right), 3.75\left(6 \mathrm{H}, \mathrm{q}, \mathrm{J}_{\mathrm{AB}} 7, \mathrm{CH}_{2}, 15-\mathrm{H}\right), 6.34(1 \mathrm{H}, \mathrm{br}$, $\mathrm{CH}, 7-\mathrm{H}), 7.20$ (1H, dd, CH, $\left.3^{\prime}-\mathrm{H}\right), 7.57$ (1H, dd, CH, 3-H), $8.15\left(1 \mathrm{H}, \mathrm{m}, \mathrm{CH}, 4^{\prime}-\mathrm{H}\right), 8.18$ (1H, br, NH, 11-H), 8.37 (1H, m, $\mathrm{CH}, 4-\mathrm{H}), 8.38(1 \mathrm{H}, \mathrm{br}, \mathrm{NH}, 9-\mathrm{H}), 8.86\left(1 \mathrm{H}, \mathrm{m}, \mathrm{CH}, 2^{\prime}-\mathrm{H}\right)$, $9.00(1 \mathrm{H}, \mathrm{m}, \mathrm{CH}, 2-\mathrm{H}) .{ }^{13} \mathrm{C}\left\{{ }^{1} \mathrm{H}\right\} \mathrm{NMR}\left(75.5 \mathrm{MHz} ; \mathrm{CDCl}_{3}, \delta_{\mathrm{c}}\right.$ ppm) 7.7 (s, $\left.\mathrm{CH}_{2}, 14\right), 18.3\left(\mathrm{~s}, \mathrm{CH}_{3}, 16\right), 23.7$ (s, $\left.\mathrm{CH}_{2}, 13\right), 42.8$ (s, $\left.\mathrm{CH}_{2}, 12\right), 58.4$ (s, $\left.\mathrm{CH}_{2}, 15\right), 118.1$ (s, $\left.\mathrm{CH}, 7\right), 122.4$ (s, CH, $3^{\prime}$ ), 123.5 (s, CH, 3), 125.0 (s, C, 6), 129.0 (s, C, 5'), 131.0 (s, $\mathrm{CH}, 4^{\prime}$ ), 132.8 (s, C, 5), 135.9 (s, CH, 4). 143.0 (s, C, 6' $), 146.2$ (s, C, 8), 149.0 (s, CH, $2^{\prime}$ ), 149.6 (s, CH, 2), 156.8 (s, C, 10).

(b) Synthesis of Complex Eu(TTA) ${ }_{3}$ (Phen-Si). The complex was prepared according to the procedure described by Duan et al. [28]. 2-Thenoyltrifluoroacetone (TTA) (6 mmol, $1.332 \mathrm{~g}$ ) was dissolved in $20 \mathrm{~mL}$ of absolute ethanol, and triethylamine $(6 \mathrm{mmol}, 0.81 \mathrm{~mL})$ was added. After $10 \mathrm{~min}$ of stirring, the ligand (Phen-Si) (2 mmol, $0.738 \mathrm{~g}$ ) was added, followed by $\mathrm{Eu}\left(\mathrm{NO}_{3}\right)_{3}(2 \mathrm{mmol}, 0.517 \mathrm{~g})$. The reaction mixture was heated at $50-60^{\circ} \mathrm{C}$ and stirred under Ar for an appropriate time $(3-5 \mathrm{~h})$. The reaction mixture was then cooled to room temperature, and the solvent was removed at $40^{\circ} \mathrm{C}$ under reduced pressure until obtaining a powder. Then the powder was washed with water and centrifuged. The crude product was then recrystallized by refluxing in ethanol to obtain the desired product which was collected by filtration and dried under vacuum at $40^{\circ} \mathrm{C}$.

Elemental analysis for $\mathrm{C}_{46} \mathrm{H}_{39} \mathrm{~N}_{4} \mathrm{O}_{10} \mathrm{~F}_{9} \mathrm{~S}_{3} \mathrm{SiEu}, \%$, found (calcd.): C 41.4 (44.0); H 3.6 (3.1); N 8.2 (8.16). SM. $(\mathrm{m} / z)$; found 839.9. Calc. for $\left(\mathrm{Eu}(\mathrm{Phen}-\mathrm{Si})(\mathrm{TTA})\left(\mathrm{NO}_{3}\right)\right)^{+}$: 837. IR $\left(\mathrm{KBr}, \mathrm{cm}^{-1}\right): 2945 v_{\text {as }}\left(\mathrm{CH}_{2}, \mathrm{CH}_{3}\right) ; 2808 v_{\mathrm{s}}\left(\mathrm{CH}_{2}, \mathrm{CH}_{3}\right) ; 1546$, 




(a)

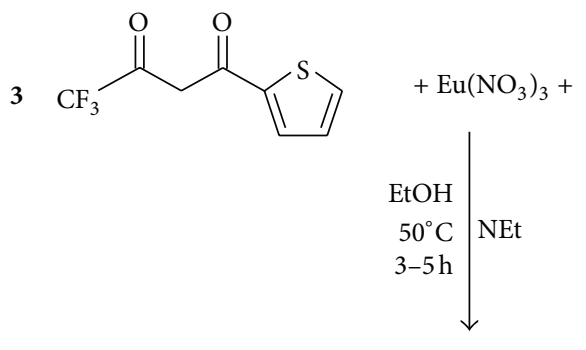<smiles>CCO[Si](CCCNC(=O)Nc1cc2cccnc2c2ncccc12)(OCC)OCC</smiles>

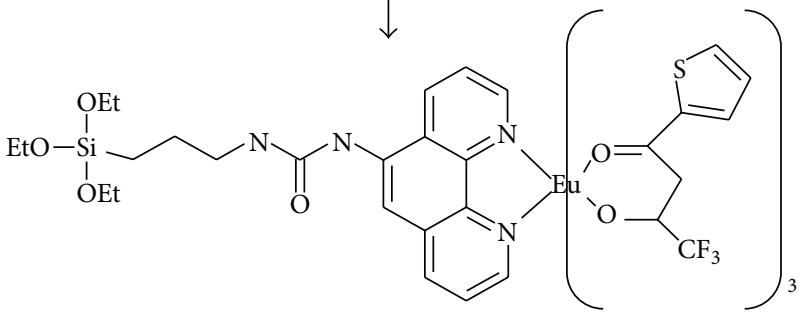

(b)

FIGURE 1: Chemical structure of (a) the silylated phenanthroline ligand (Phen-Si) (and carbon atom numbering related to NMR data) and (b) the $\mathrm{Eu}(\mathrm{TTA})_{3}(\mathrm{Phen}-\mathrm{Si})$ complex.

$1500 \nu(\mathrm{C}=\mathrm{O}) ; 1440,1423,1385 \nu_{\text {as }}(\mathrm{C}-\mathrm{C}=\mathrm{C})$ aromatic; 737, 668 $\gamma(=\mathrm{C}-\mathrm{H})$ aromatic.

(c) Grafting of Eu(TTA $)_{3}$ (Phen-Si) into $\mathrm{mSiO}_{2}$ Nanoparticles. The grafting was carried out according to a modified protocol from Rocha et al. [27]. $\mathrm{mSiO}_{2} \mathrm{NPs}$ were suspended in DMF. $94.2 \mu \mathrm{mol} / \mathrm{g}$ of $\mathrm{Eu}(\mathrm{TTA})_{3}$ (Phen-Si) complex was also suspended with DMF. Then the two suspensions were mixed, and the final concentration of $\mathrm{mSiO}_{2}$ was $1 \mathrm{mg} / \mathrm{mL}$. The mixture was refluxed for $24 \mathrm{~h}$. The powder was then centrifuged, washed three times with ethanol, and dried at $80^{\circ} \mathrm{C}$ in an oven overnight. The europium content, determined by TEM-EDX, is $0.1 \%(\mathrm{~mol})$.

\subsubsection{Synthesis of Si-DBM-Eu(DBM $)_{2}$ Complex and Grafting in $\mathrm{mSiO}_{2}$}

(a) Preparation of Sodium $\beta$-Diketonate (Na-DBM). The ligand was prepared according to the procedure described by Machado et al. [29] and De Oliveira et al. [30]. $\mathrm{Na}$ (s) (0.7 g, $30.0 \mathrm{mmol}$ ) was dissolved in $30 \mathrm{~mL}$ of anhydrous methanol under an argon atmosphere to produce sodium methoxide. $6.7 \mathrm{~g}(30.0 \mathrm{mmol})$ of dibenzoylmethane (DBM) was added to the methoxide solvent to obtain a viscous suspension. Subsequently, the powder was collected by filtration, washed with anhydrous methanol, and dried under vacuum at $50^{\circ} \mathrm{C}$ producing Na-DBM with a yield of $85 \%$.

(b) Synthesis of Silylant Agent with 3-Chloropropyltrimethoxysilane (TMOSCl). TMOSCl $(1.13 \mathrm{~mL}, 6.0 \mathrm{mmol})$ and $1.482 \mathrm{~g}(6.0 \mathrm{mmol})$ of $\mathrm{Na}-\mathrm{DBM}$ were added to $30 \mathrm{~mL}$ of anhydrous methanol. The solution was stirred under argon atmosphere at $50^{\circ} \mathrm{C}$ for $24 \mathrm{~h}$. The silylating agent was denoted by $\mathrm{Na}(\mathrm{Si}-\mathrm{DBM})$. Figure 2 shows the chemical structure that represents this process.

(c) Grafting of $\mathrm{Na}(\mathrm{Si}-\mathrm{DBM})$ inside $\mathrm{mSiO}_{2}$ Nanoparticles, Complexation with $\mathrm{Eu}^{3+}$. The grafting was carried out according to a modified protocol from Rocha et al. [27]. $\mathrm{mSiO}_{2} \mathrm{NPs}$ (50 mg) were added to anhydrous ethanol ( $0.35 \mathrm{~mol})$ and $30 \%$ $\mathrm{NH}_{4} \mathrm{OH}(10 \mathrm{mmol})$ mixture. $\mathrm{Na}(\mathrm{Si}-\mathrm{DBM})$ solution $(1.31 \mathrm{~mL})$ was then added to the above mixture that was then stirred for $1 \mathrm{~h}$. The powder was then centrifuged, washed three times with ethanol, and dried at $50^{\circ} \mathrm{C}$ in an oven overnight. Finally, the powder was suspended in anhydrous ethanol $(10 \mathrm{~mL})$ containing $\mathrm{EuCl}_{3}\left(2.35 \mathrm{~mL}, 0.10 \mathrm{~mol} \cdot \mathrm{L}^{-1}\right)$, producing $\mathrm{mSiO}_{2}-\mathrm{Eu}(\mathrm{Si}-\mathrm{DBM})$. To complete the coordination sphere of $\mathrm{Eu}^{3+}, 20 \mathrm{mg}$ of DBM-Na was added to produce the final luminescent material, SiDBM-Eu(DBM $)_{2}$ [30]. The powder was again centrifuged, washed three times with ethanol, and dried at $50^{\circ} \mathrm{C}$ in an oven overnight. 




FIGURE 2: Chemical structure of the silylated $\mathrm{Na}(\mathrm{Si}-\mathrm{DBM})$ ligand [27].



FIgURE 3: FTIR spectrum of Si-DBM-Eu(DBM $)_{2}$.

FTIR spectrum of sample is presented Figure 3. The typical bands of both DBM and silica structure, such as a large band centered on $3434 \mathrm{~cm}^{-1}$, assigned to $\mathrm{OH}$ stretching of silanol groups of inorganic mesoporous structure of material and also adsorbed and/or bonded water can be seen. Three peaks at 2964,2923 , and $2852 \mathrm{~cm}^{-1}$ are related to $\mathrm{C}-\mathrm{H}$ stretching of $\mathrm{CH}_{2}$ and $\mathrm{CH}_{3}$ groups. The mesoporous silica structure can also be seen with the bands at 1065, 805, and $455 \mathrm{~cm}^{-1}$, corresponding to the different $\mathrm{Si}-\mathrm{O}-\mathrm{Si}$ vibrations (stretching, bending, and rocking, resp.). Signal related to the beta-diketone can also be observed with the four bands at $1597,1548,1458$, and $1313 \mathrm{~cm}^{-1}$, corresponding, respectively, to $\nu_{\text {as }}(\mathrm{C}=\mathrm{O}), v(\mathrm{C}=\mathrm{C}), \nu_{\mathrm{s}}(\mathrm{C}=\mathrm{O})$, and $\nu_{\text {as }}(\mathrm{C}-\mathrm{C})$ of DBM [30]. Europium content has been quantified by EDX-MET and has been found to be $0.04 \%$ (mol).

\subsubsection{Impregnation of $m \mathrm{SiO}_{2} \mathrm{NPs}$ with $\mathrm{Eu}(\mathrm{DBM})_{3}$ (Phen) and $\mathrm{Eu}(\mathrm{BHHCT})$ Complexes}

(a) Synthesis of $\mathrm{Eu}(\mathrm{DBM})_{3}$ (Phen) and $\mathrm{mSiO}_{2}$ Impregnation. The complex was prepared according to Melby et al. [31] with some modifications. The ligand was first deprotonated by addition of $113.6 \mu \mathrm{L}$ of a solution of $\mathrm{KOH}$ in methanol
$0.990 \mathrm{~mol} \cdot \mathrm{L}^{-1}$ to $750 \mu \mathrm{L}$ of an ethanolic solution of dibenzoylmethane (DBM) $0.150 \mathrm{~mol} \cdot \mathrm{L}^{-1}$, followed by $375 \mu \mathrm{L}$ of an ethanolic solution of 1,10 -phenantroline $0.1 \mathrm{~mol} \cdot \mathrm{L}^{-1}$. Then, $375 \mu \mathrm{L}$ of an aqueous solution of $\mathrm{Eu}\left(\mathrm{NO}_{3}\right)_{3} 0.1 \mathrm{~mol} \cdot \mathrm{L}^{-1}$ was added dropwise under magnetic stirring, to give the precipitated complex $\left[\mathrm{Eu}(\mathrm{DBM})_{3}(\mathrm{Phen})\right]$. This suspension was stirred for $24 \mathrm{~h}$ at room temperature and then centrifuged. The precipitate was carefully washed with ethanol, recovered by centrifugation, and dried at $60^{\circ} \mathrm{C}$ in air overnight. The complex was then dissolved in DMSO and stirred with $30 \mathrm{mg}$ of mesoporous silica nanoparticles during $24 \mathrm{~h}$ at room temperature, in order to encapsulate it. The amount of europium complex impregnated was calculated to be $6.25 \mu \mathrm{mol}$ per $5 \mathrm{mg}$ of mesoporous silica. Finally, the sample was coated with silica-amine shell as described in the next topics. After analysis, the $\mathrm{Eu}^{3+}$ content has found to be $0.42 \%$ (mol).

(b) Synthesis of $\mathrm{Eu}(\mathrm{BHHCT})$ Complex and $\mathrm{mSiO}_{2}$ Impregnation. The ligand 4,40-bis $\left(1^{\prime \prime}, 1^{\prime \prime}, 1^{\prime \prime}, 2^{\prime \prime}, 2^{\prime \prime}, 3^{\prime \prime}, 3^{\prime \prime}\right.$-heptafluoro$4^{\prime \prime}, 6^{\prime \prime}$-hexanedion- $6^{\prime \prime}$-yl) chlorosulfo-o-terphenyl (BHHCT) was prepared as previously reported [32]. In order to form the complex Eu-BHHCT, $5 \mathrm{mg}(6.25 \mu \mathrm{mol})$ of BHHCT ligand was dissolved in $15 \mathrm{~mL}$ of propanol. $2.29 \mathrm{mg}(6.25 \mu \mathrm{mol})$ of $\mathrm{EuCl}_{3} \cdot 6 \mathrm{H}_{2} \mathrm{O}$ was dissolved in $0.25 \mathrm{~mL}$ of distilled water and then added to the BHHCT solution. The mixture was aged at room temperature in darkness, in order to form the complex. Then, $5 \mathrm{mg}$ of mesoporous silica nanoparticles was added to the complex solution, and the suspension was kept under stirring for one night, at room temperature, in darkness. In order to prevent any leak of the impregnated complex, the silica coating was elaborated without any purification. However, after silica coating, $\mathrm{Eu}^{3+}$ content has been determined by MET-EDX and was found to be $1 \%(\mathrm{~mol})$.

(c) Aminosilane Coating. In order to avoid the leak of the impregnated complexes, the nanocapsules were closed by coating them with a thin silica layer. Typically $30 \mathrm{mg}$ of impregnated silica nanoparticles was dissolved in $80 \mathrm{~mL}$ of propanol under ultrasound for $2 \mathrm{~h}$. Then, $8.94 \mathrm{~mL}$ of $\mathrm{NH}_{4} \mathrm{OH}$ (28\%), $7.5 \mathrm{~mL}$ of distilled water, and $25 \mu \mathrm{L}$ of TEOS were added to the mixture and stirred at $40^{\circ} \mathrm{C}$ for $2 \mathrm{~h}$. Then, $100 \mu \mathrm{L}$ of (3-aminopropyl)trimethoxysilane (APTMS) was added and the mixture stirred for 1 more hour. The reaction 


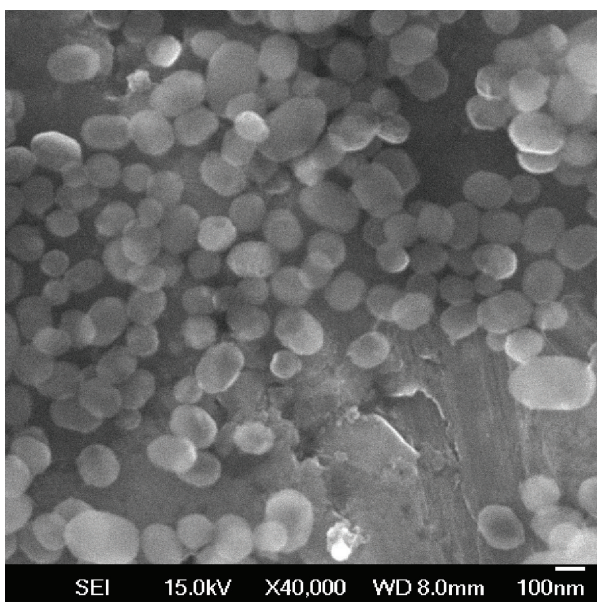

(a)

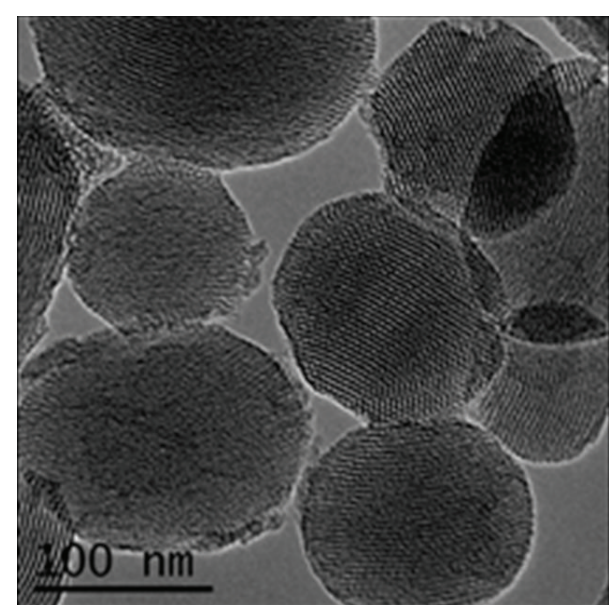

(b)

Figure 4: SEM (a) and TEM (b) images of synthetized mesoporous silica nanoparticles $\left(\mathrm{mSiO}_{2}\right)$.

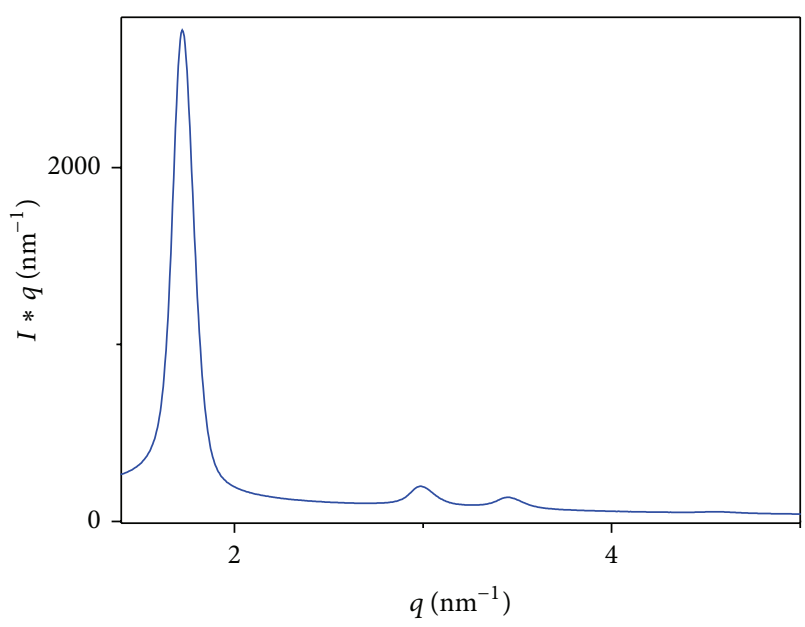

FIGURE 5: SAXS diagram of synthetized mesoporous silica nanoparticles $\left(\mathrm{mSiO}_{2}\right)$.

mixture is then centrifuged and washed with propanol, and the obtained precipitate is dried in oven overnight. The final weight of the material was approximately $45 \mathrm{mg}$. Note that the APTMS molecule does not play any role to prevent the dye release. This molecule has been added at the end of the coating protocol in order to introduce amine functions which are very useful for further biofunctionalization.

2.3. Physical and Chemical Characterizations. ${ }^{1} \mathrm{H}$ and ${ }^{13} \mathrm{C}$ NMR spectra were recorded on Bruker Advance 300 , with chemical shifts (in $\mathrm{ppm}$ ) reported relative to tetramethylsilane. Mass spectra were recorded by FAB or IS techniques using a Normas R10-10 spectrometer. Elemental analyses were performed on elementary analyses (EA) which were performed using a Perkin Elmer 2400 series II elemental analyser. Chemical bonding was characterized by infrared spectroscopy using a Perkin Elmer spectrometer 100 series. Samples were prepared by mixing the powders with potassium bromide (1/100 by weight) in a pellet. Nitrogen adsorption-desorption curves were measured with a Belsorp-mini (BEL Japan Inc.) between 0 and $99 \mathrm{p} / \mathrm{p}_{0}$ at $77 \mathrm{~K}$. Pretreatment was performed under vacuum during $24 \mathrm{~h}$ at $80^{\circ} \mathrm{C}$. Small angle X-ray scattering (SAXS) analyses were performed on an INEL XRG3D device. Small angle X-ray scattering signal from mesoporous silica was obtained with $\mathrm{X}$-rays produced by a $\mathrm{Cu}$ anode. The $\mathrm{X}$-ray beam was then filtered and focused onto the specimen using KirkpatrickBaez mirrors, thus delimiting a small and nondivergent beam. Scattered intensity was recorded on an imaging plate, located $38 \mathrm{~cm}$ behind the specimen. Particle shape, size, and composition were examinated by Transmission Electron Microscopy (TEM) using Philips CM20 FEG microscope, equipped with EDX detector. This EDX detector was used to quantify Eu contents of samples. Fluorescence spectra were recorded with a Fluorolog FL3-22 Jobin Yvon spectrometer equipped with a R928 Hamamatsu photomultiplier and a $450 \mathrm{~W}$ excitation lamp. For the analysis of emission decay versus time, a pulsed Xe source was employed. The emission decays have been recorded under excitation at $365 \mathrm{~nm}$, monitoring the ${ }^{5} \mathrm{D}_{0} \rightarrow{ }^{7} \mathrm{~F}_{2}$ at its maximum $(612 \mathrm{~nm})$. Experimental decays have been calculated according the formula $\tau=\left[\int_{0}^{\infty} t * I(t) d t\right] /\left[\int_{0}^{\infty} I(t)\right]$, with an error range estimated to be $15 \%$.

2.4. Cell Culture, Cytotoxicity Test, and Fluorescence Imaging. An indirect cytotoxicity test was performed using an elution method as described previously [33]. The used cells are MDAMB231 which are triple negative breast cancer cells [34]. The cells are maintained in culture in RPMI 1640 medium complemented with $10 \%$ fetal bovine serum, $1 \%$ penicillinstreptomycin and incubated at $37^{\circ} \mathrm{C}$ with $5 \% \mathrm{CO}_{2}$. For in vitro labeling as for cytotoxic tests, cells were placed in 96-well plate at 10000 cells/well. The particles were added at different concentrations to the cell medium after sonication. The MTT (methyl thiazoletetrazolium, Sigma) test is used to evaluate the viability of the MDA-MB231 in the presence of different 


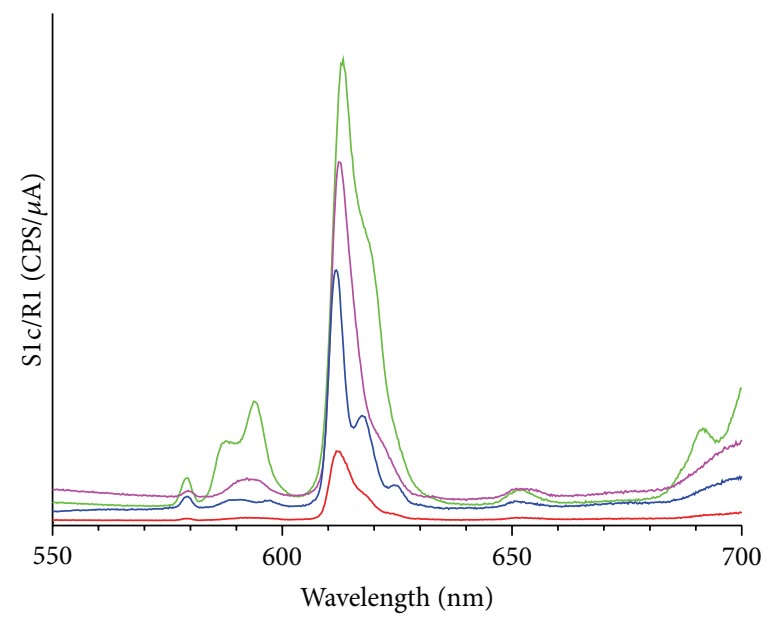

$\begin{array}{ll}\mathrm{mSiO}_{2}-\mathrm{Eu}(\mathrm{Si}-\mathrm{DBM}) & -\mathrm{mSiO}_{2} @ \mathrm{Eu}-\mathrm{BHHCT} \\ \mathrm{mSiO}_{2}-\mathrm{Eu}(\mathrm{TTA})_{3}(\text { Phen-Si })-\mathrm{mSiO}_{2} @ \mathrm{Eu}(\mathrm{DBM})_{3} \mathrm{Phen}\end{array}$

(a)

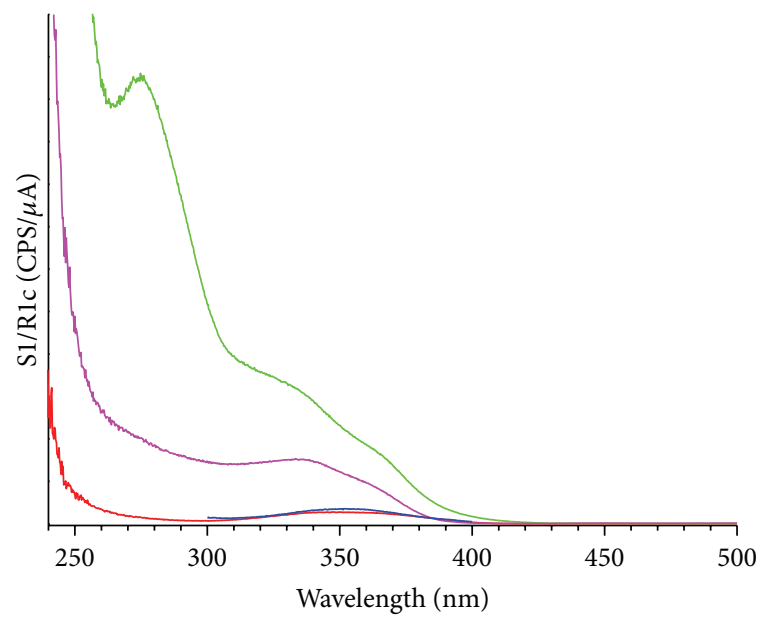

$\mathrm{mSiO}_{2}-\mathrm{Eu}(\mathrm{Si}-\mathrm{DBM})$ $\mathrm{mSiO}_{2}-\mathrm{Eu}(\mathrm{TTA})_{3}$ (Phen-Si)

$\mathrm{mSiO}_{2} @ \mathrm{Eu}-\mathrm{BHHCT}$ $\mathrm{mSiO}_{2} @ \mathrm{Eu}(\mathrm{DBM})_{3}$ Phen

(b)

Figure 6: (a) Emission spectra $\left(\lambda_{\text {ex }}=365 \mathrm{~nm}\right)$ and (b) excitation spectra $\left(\lambda_{\text {em }}=612 \mathrm{~nm}\right)$ of Eu(Si-DBM $)_{3}, \mathrm{Eu}(\mathrm{DBM})_{3}$-Phen, Eu-BHHCT, and $\mathrm{Eu}(\mathrm{TTA})_{3}$ (Phen-Si) complexes incorporated in $\mathrm{mSiO}_{2}$. Particle concentration $=0.25 \mathrm{mg} \cdot \mathrm{mL}^{-1}$ in water.

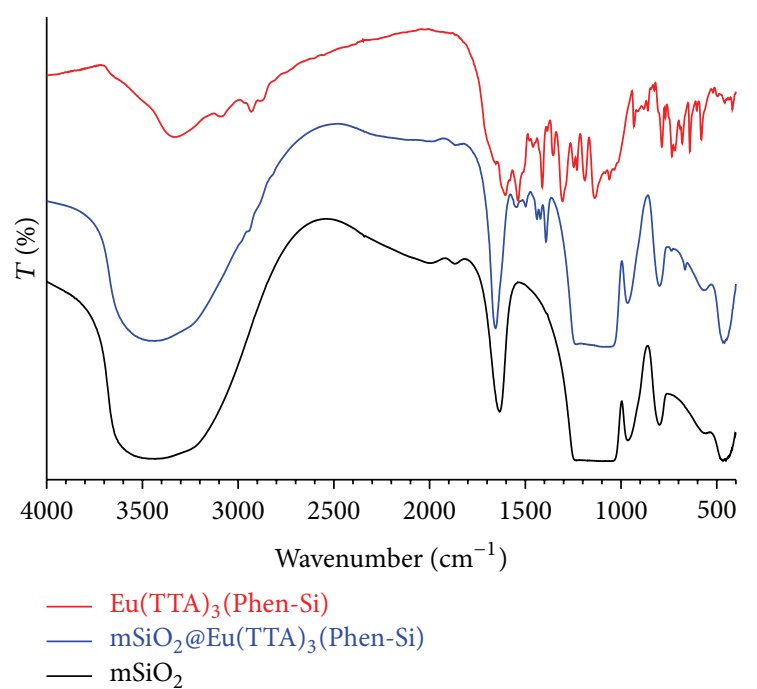

Figure 7: IR spectra of $\mathrm{mSiO}_{2}, \mathrm{Eu}(\mathrm{TTA})_{3}(\mathrm{Phen}-\mathrm{Si})$, and $\mathrm{mSiO}_{2}$ $\mathrm{Eu}(\mathrm{TTA})_{3}(\mathrm{Phen}-\mathrm{Si})$.

concentrations of the NPs $\left(\mathrm{mSiO}_{2}-\mathrm{Eu}(\mathrm{TTA})_{3}(\mathrm{Phen}-\mathrm{Si})\right)$ one and three days after their addition to cell culture medium. MTT test is a colorimetric assay for measuring the activity of enzymes that reduce MTT to formazan dye, giving a purple color. DMSO (dimethylsulfoxide) solution is added to dissolve the insoluble purple formazan product into a colored solution. The absorbance of this colored solution can be quantified by measuring at $570 \mathrm{~nm}$ by a spectrophotometer.

For in vitro labeling, cells were incubated with NPs $(0.1 \mathrm{mg} / \mathrm{mL}, 24 \mathrm{~h})$. Microscopic images were obtained using a "home-made" Time Gated Luminescence Microscope (TGLM) kindly built for us by Dr. Dayong Jin from Macquarie University of Sydney. The main interest of a TGLM is to be able to separate long-lasting fluorescence coming from lanthanides from self-fluorescence coming from the biological media [23].

\section{Results and Discussion}

3.1. Synthesis of Mesoporous Silica Nanoparticles. The synthesis procedure is based on the protocol proposed by [35]. After a full optimization procedure with many varying parameters as reactant concentration (TEOS: $0.93 \mathrm{mmol}$ to $4.7 \mathrm{mmol}$ and CTAB: $0.77 \mathrm{mmol}$ to $7.1 \mathrm{mmol})$, temperature $\left(25\right.$ to $\left.90^{\circ} \mathrm{C}\right)$, and reaction time ( 2 to $20 \mathrm{~h}$ ), we find that the best results (average size close to $100 \mathrm{~nm}$, spherical shape, no agglomeration, high surface area, and a high porous volume) were obtained with the procedure reported in Section 2. Figure 4 shows SEM images (a) of particles. Average particle size (feret diameter, counted on 242 particles) is $116 \mathrm{~nm}$ with a standard deviation of $45 \mathrm{~nm}$. On the TEM image of Figure 4(b) one can clearly see the well-ordered mesoporous structure of particles. SAXS analysis presented in Figure 5 is characteristic of a hexagonal MCM 41 well-organized mesostructure [36] with three visible diffraction peaks: $d(100)=3.37 \AA, d(110)$ $=2.22 \AA$, and $d(200)=1.91 \AA$. The adsorption/desorption isotherm (BET) experiments done at $77 \mathrm{~K}$ under nitrogen give a specific surface area equal to $1018 \mathrm{~m}^{2} \mathrm{~g}^{-1}$. The average pore size is centered at $5.476 \mathrm{~nm}$ whereas total porous volume is estimated at $1.397 \mathrm{~cm}^{3} \mathrm{~g}^{-1}$.

3.2. Comparison of Luminescent Properties of Eu Complexes Incorporated in $\mathrm{mSiO}_{2}$. In order to verify that no release of complexes occurs in aqueous solution we have checked that nanoplatforms do not lose luminescence intensity $(<5 \%)$ after severe water leaching $(3 \times 1 \mathrm{~h}$ in water). Then, to compare performance of the different luminescent nanoplatforms 




(a)

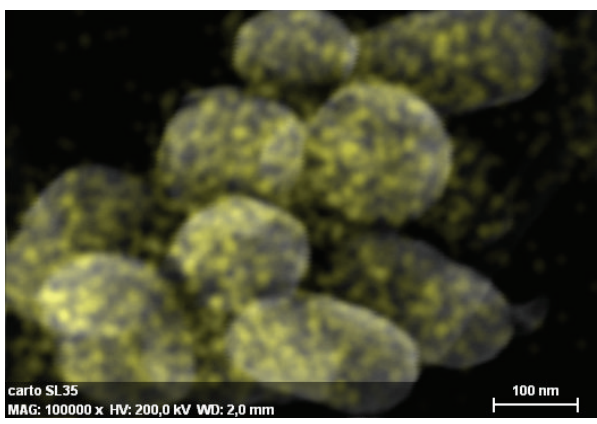

(c)



(b)

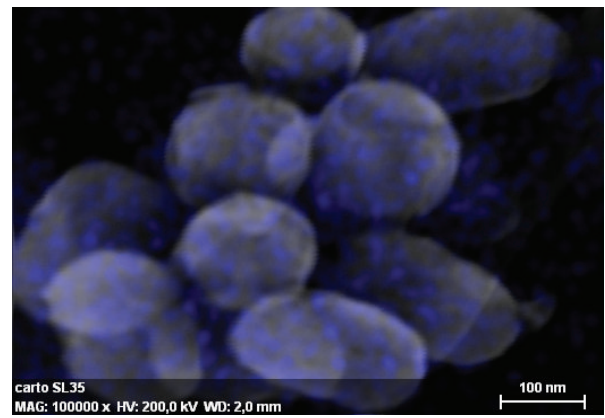

(d)

Figure 8: Electron microscope images and elemental cartography of $\mathrm{mSiO}_{2}$-Eu(TTA) ${ }_{3}$ (Phen-Si). (a) STEM image, (b) Si cartography, (c) $\mathrm{N}$ cartography, and (d) Eu cartography.

we have recorded an emission spectrum after excitation at $365 \mathrm{~nm}$ (laser diode or $\mathrm{Hg}$ lamp wave length usually found on many epifluorescence microscope) under exactly the same condition $\left(0.25 \mathrm{mg} \cdot \mathrm{mL}^{-1}\right.$ of NPs in water). Results, presented in Figure 6, show that all complexes have a maximum emission band centred around $613 \mathrm{~nm}$. However, emission intensities, recorded under the same conditions, are different. The sample presenting the most intense luminescence is the one with $\mathrm{Eu}(\mathrm{TTA})_{3}(\mathrm{Phen}-\mathrm{Si})$ complex, grafted inside the mesopores of the $\mathrm{mSiO}_{2} \mathrm{NPs}$. As this sample presents the highest luminescent intensity, it has been selected for further characterization.

3.3. Characterization of the Eu(TTA) $)_{3}$ (Phen-Si) Complex Grafted in $\mathrm{mSiO}_{2}$. Eu(TTA) $)_{3}$ (Phen-Si) complex was successfully prepared via a two steps process as shown in Figure 1. Ligand (Phen-Si) was first obtained by reacting 5amino-1,10-phenanthroline and 3-(triethoxysilyl)propyl isocyanate (Figure 1(a)). Europium complex was then prepared from $\mathrm{Eu}\left(\mathrm{NO}_{3}\right)_{3}, 2$-thenoyltrifluoroacetone (TTA), and phenantroline ligand (Phen-Si) in the presence of triethylamine in ethanol at $50-60^{\circ} \mathrm{C}$ (Figure $1(\mathrm{~b})$ ). Figure 7 shows infrared spectra of $\mathrm{Eu}(\mathrm{TTA})_{3}$ (Phen-Si) complex, $\mathrm{mSiO}_{2}$, and the sample of $\mathrm{mSiO}_{2}$ incorporating the complex $\left(\mathrm{mSiO}_{2}\right.$ $\left.\mathrm{Eu}(\mathrm{TTA})_{3}(\mathrm{Phen}-\mathrm{Si})\right)$. The spectrum of the complex presents the characteristic bands of phenanthroline as well as those of TTA, indicating that the complex has been obtained. On the $\mathrm{mSiO}_{2}$ spectrum, the well-known bands of $\mathrm{SiO}_{2}$ are observed. The $\mathrm{mSiO}_{2}-\mathrm{Eu}(\mathrm{TTA})_{3}$ (Phen-Si) spectrum exhibits both bands of the complex and $\mathrm{mSiO}_{2}$, especially in the region of $1700-600 \mathrm{~cm}^{-1}$.

The sample $\mathrm{mSiO}_{2}$-Eu(TTA) ${ }_{3}$ (Phen-Si) has also been investigated by BET analysis. After loading, the porous volume decreases down to $0.9570 \mathrm{~m}^{3} \cdot \mathrm{g}^{-1}$ (instead of $\left.1.397 \mathrm{~m}^{3} \cdot \mathrm{g}^{-1}\right)$, as well as the specific area to $684 \mathrm{~m}^{2} \cdot \mathrm{g}^{-1}$ (instead of $1018 \mathrm{~m}^{2} \cdot \mathrm{g}^{-1}$ ). This loss of porous volume and specific area confirms that the complex Eu(TTA) ${ }_{3}$ (Phen-Si) is well grafted into the mesopores of the NPs.

Figure 8 presents the elemental cartography obtained by EDX spectroscopy on STEM microscopy. It can be seen that after incorporation, $\mathrm{mSiO}_{2}$ keeps its spherical shape without any aggregation. EDX spectroscopy results show that silicon atoms are homogenously dispersed to form the mesoporous silica matrix (Figure 8(b)). Nitrogen and europium atoms are also detected, corresponding to the grafted complex (Figures $8(\mathrm{c})$ and $8(\mathrm{~d})$ ). Images reveal that these elements are homogenously well dispersed all inside the NPs, confirming the good repartition of the complex, all around the walls of the mesoporous silica.

In Figure 9(a) emission spectra of the grafted complex recorded in ethanol after excitation at $365 \mathrm{~nm}$ are gathered. For the free complex the concentration was $0.25 \mathrm{mg} \cdot \mathrm{mL}^{-1}$, corresponding to $2 \cdot 10^{-4} \mathrm{~mol} \cdot \mathrm{L}^{-1}$ in $\mathrm{Eu}^{3+}$, and for the grafted complex the concentration was $1 \mathrm{mg} \cdot \mathrm{mL}^{-1}$, corresponding to $2 \cdot 10^{-5} \mathrm{~mol} / \mathrm{L}$ in $\mathrm{Eu}^{3+}$ (considering a grafting rate of $0.1 \%(\mathrm{~mol})$ ). The characteristic emission lines of transitions ${ }^{5} \mathrm{D}_{0} \rightarrow{ }^{7} \mathrm{~F}_{J}$ of $\mathrm{Eu}^{3+}$ are observed for both samples. Some differences may be noticed: for instance, the shape of the 


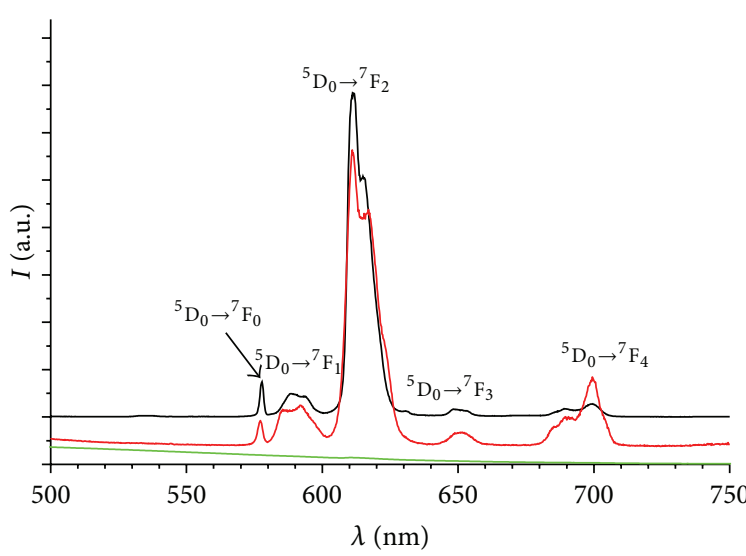

$\mathrm{Eu}(\mathrm{TTA})_{3}(\mathrm{Phen}-\mathrm{Si})$ $\mathrm{mSiO}_{2}-\mathrm{Eu}(\mathrm{TTA})_{3}$ (Phen-Si) $-\mathrm{mSiO}_{2}$

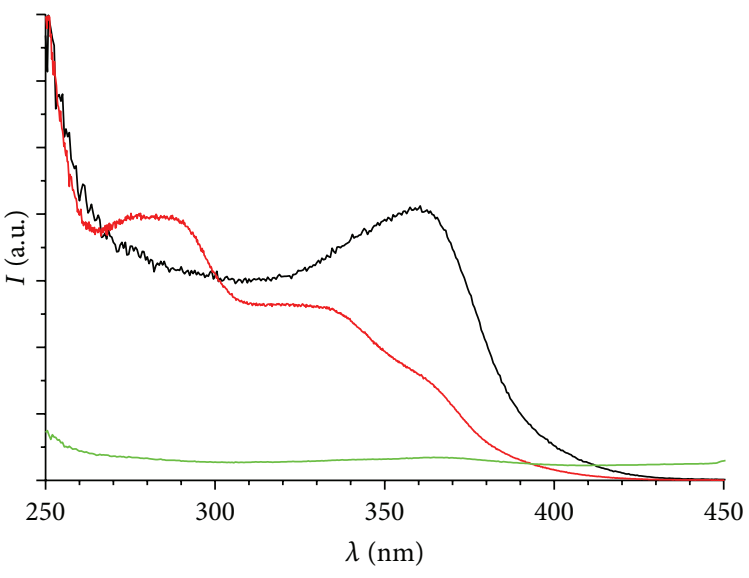

- $\mathrm{Eu}(\mathrm{TTA})_{3}($ Phen-Si)
$\mathrm{mSiO}_{2}-\mathrm{Eu}(\mathrm{TTA})_{3}$ (Phen-Si)

(b)

(a)

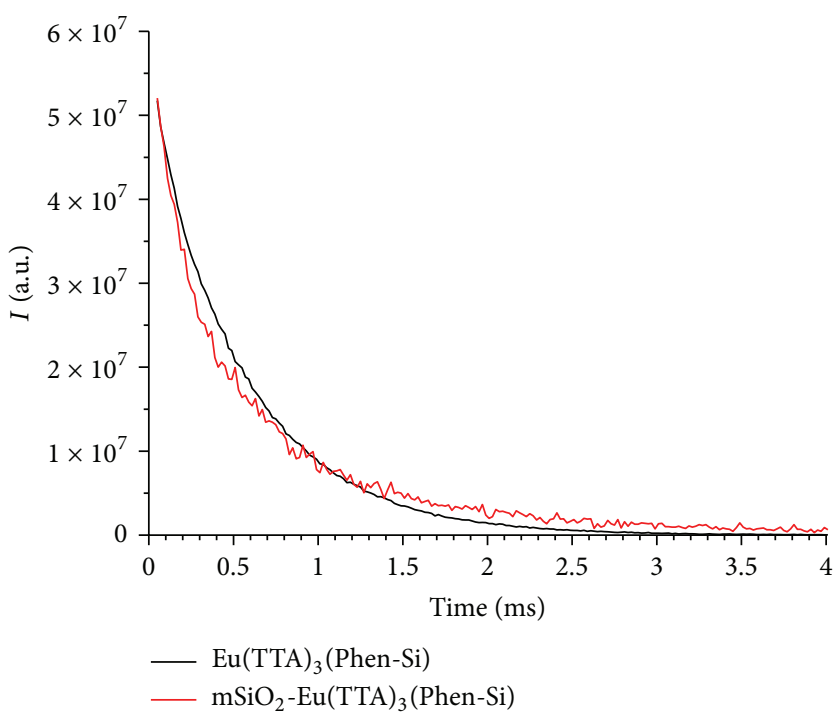

(c)

FiguRE 9: (a) Emission spectra recorded after excitation at $365 \mathrm{~nm}$, (b) excitation spectra recorded at $612 \mathrm{~nm}$, and (c) emission decay curves recorded at $612 \mathrm{~nm}$ under excitation at $365 \mathrm{~nm}$ for pure $\mathrm{Eu}(\mathrm{TTA})_{3}(\mathrm{Phen}-\mathrm{Si})$ complex and $\mathrm{mSiO}_{2}-\mathrm{Eu}(\mathrm{TTA})_{3}(\mathrm{Phen}-\mathrm{Si})$.



Figure 10: Cytotoxicity test of $\mathrm{mSiO}_{2}-\mathrm{Eu}(\mathrm{TTA})_{3}$ (Phen-Si). The higher is the DO, the higher is the living cells number.
${ }^{5} \mathrm{D}_{0} \rightarrow{ }^{7} \mathrm{~F}_{1_{7}}$ transition and relative intensities of ${ }^{5} \mathrm{D}_{0} \rightarrow$ ${ }^{7} \mathrm{~F}_{4} /{ }^{5} \mathrm{D}_{0} \rightarrow{ }^{7} \mathrm{~F}_{2}$. Figure 9 (b) presents excitation spectra for these samples observed at $612 \mathrm{~nm}$. For the free complex, one broad band centred on $360 \mathrm{~nm}$ can be seen. After incorporation into $\mathrm{mSiO}_{2}$ this broad band remains, but seems to be shifted to higher energy, around $330 \mathrm{~nm}$. This is probably due to the covalent grafting of the complex into $\mathrm{mSiO}_{2}$, which modifies energy transfers from the antenna to $\mathrm{Eu}^{3+}$ ions. The ${ }^{5} \mathrm{D}_{0}$ luminescence decays for the free complex and the complex grafted into $\mathrm{mSiO}_{2}$ are shown in Figure 9 (c). The free complex exhibits monoexponential decay $I=I_{0} \cdot e(-t / \tau)$ with lifetime $\tau=0.6 \pm 0.06 \mathrm{~ms}$. For grafted complex, the decay is clearly biexponential: the faster component is the same as for pure complex, but a slower component with lifetime 




(a)



(b)

Figure 11: Internalization of $\mathrm{mSiO}_{2}-\mathrm{Eu}(\mathrm{TTA})_{3}(\mathrm{Phen}-\mathrm{Si})$ in MDA-MB231 cancer cells after exposure to NPs (overnight, $\left.0.1 \mathrm{mg} \cdot \mathrm{mL}^{-1}\right)$. (a) Representative bright field images + UV excitation $\left(\lambda_{\mathrm{ex}}: 365 \mathrm{~nm}\right.$, the blue color comes from the nucleus colored with DAPE used to help cells detection). (b) UV excitation $\left(\lambda_{\text {ex }}: 365 \mathrm{~nm}\right)$ and time gated detection of Eu(TTA $)_{3}$ (Phen-Si).

estimated to about $1 \mathrm{~ms}$ is also observed. The average decay, estimated with the formula $\tau=\left[\int_{0}^{\infty} t * I(t) d t\right] /\left[\int_{0}^{\infty} I(t)\right]$, is $\tau=0.80 \pm 0.08 \mathrm{~ms}$. From the comparison of emission spectra and of emission decays, at least two populations of $\mathrm{Eu}^{3+}$ are then observed after grafting into $\mathrm{mSiO}_{2}$. A detailed investigation of luminescence data, necessary to discuss the possible structures of these populations, is beyond the scope of this paper. It is important to notice here two essential features for the potential applications. The first point is the red emission observed for the dispersed NPs and the pure complex in solution, both excited at $365 \mathrm{~nm}$, that is, in the organic antenna, and recorded under the same experimental conditions and have the same intensities. The other point of interest is that the emission lifetime of the grafted NPs is suitable for microsecond time gated detection of luminescence.

3.4. Cytotoxicity Tests on Nanoparticles. The optical density (OD) is directly proportional to the living cells number. The comparison of the proliferation of MDA-MB231 cancer cells, in contact (during 3 days) with growing concentrations of NPs $0.1 ; 0.5 ; 1$; and $2 \mathrm{mg} / \mathrm{mL}$, emphasizes a significant decrease of cell viability, and an inhibition of cell growth for doses of NPs higher than $0.1 \mathrm{mg} \cdot \mathrm{mL}^{-1}$ (Figure 10). Nevertheless, for particles of concentration around $100 \mu \mathrm{g} \cdot \mathrm{mL}^{-1}$, we consider that the cytotoxicity of NPs is negligible.

3.5. Observation of Particles Fluorescence in Living Cells. The spherical $\mathrm{mSiO}_{2}-\mathrm{Eu}(\mathrm{TTA})_{3}$ (Phen-Si) NPs have been allowed to react with MDA-MB231 cancer cells under conditions where NPs are shown to be noncytotoxic $\left(0.1 \mathrm{mg} \cdot \mathrm{mL}^{-1}\right)$ overnight. Images in Figure 11 show that NPs have been internalized by the cells. Indeed, a strong red fluorescence is observed in their cytoplasm with a higher intensity in the perinuclear area. The nucleus, stained in blue with DAPE, appears to be totally free of NPs as shown by time gated detection. Time gated detection collects the emission light only $100 \mu$ s after the excitation, keeping only the long-lasting luminescence of $\mathrm{Eu}^{3+}$ and removing all the background coming from the DAPE dye and self-fluorescence of the biological media [14].

\section{Conclusion}

We have synthesized new hybrid nanoplatforms for luminescent biolabeling based on the concept of $\mathrm{Eu}^{3+}$ complexes encapsulation inside mesoporous silica nanoparticles. Europium complexes have been selected on the basis of their capability to be exited at $365 \mathrm{~nm}$ which is a wavelength currently available on routine epifluorescence microscope. For $\mathrm{Eu}^{3+}$ complexes encapsulation two different routes have been used: the first route consists in grafting the transition metal complexes into the silica wall surface. The second way deals with physicochemical impregnation of the mesoporous silica NPs with the Eu complex. Then a silica shell coating will prevent any dye release. For this last protocol, the best result has been obtained using Eu-BHHCCT complex. However the best solution appears to be $\mathrm{Eu}(\mathrm{TTA})_{3}(\mathrm{Phen}-\mathrm{Si})$ complex covalently grafted inside the mesoporous silica NPs.

\section{References}

[1] B. I. Slowing, B. G. Trewyn, S. Giri, and V. S.-Y. Lin, "Mesoporous silica nanoparticles for drug delivery and biosensing applications," Advanced Functional Materials, vol. 17, no. 8, pp. 1225-1236, 2007.

[2] S. Huh, J. W. Wiench, J.-C. Yoo, M. Pruski, and V. S.-Y. Lin, "Organic functionalization and morphology control of 
mesoporous silicas via a co-condensation synthesis method," Chemistry of Materials, vol. 15, no. 22, pp. 4247-4256, 2003.

[3] B. G. Trewyn, C. M. Whitman, and V. S.-Y. Lin, "Morphological control of room-temperature ionic liquid templated mesoporous silica nanoparticles for controlled release of antibacterial agents," Nano Letters, vol. 4, no. 11, pp. 2139-2143, 2004.

[4] K. Suzuki, K. Ikari, and H. Imai, "Synthesis of silica nanoparticles having a well-ordered mesostructure using a double surfactant system," Journal of the American Chemical Society, vol. 126, no. 2, pp. 462-463, 2004.

[5] J. Y. Ying, "Design and synthesis of nanostructured catalysts," Chemical Engineering Science, vol. 61, no. 5, pp. 1540-1548, 2006.

[6] J. Y. Ying, C. P. Mehnert, and M. S. Wong, "A new type of metalorganic large-pore zeotype," Angewandte Chemie, vol. 38, no. 12, pp. 153-156, 1999.

[7] C. T. Kresge, M. E. Leonowicz, W. J. Roth, J. C. Vartuli, and J. S. Beck, "Ordered mesoporous molecular sieves synthesized by a liquid-crystal template mechanism," Nature, vol. 359, no. 6397, pp. 710-712, 1992.

[8] D. R. Radu, C.-Y. Lai, K. Jeftinija, E. W. Rowe, S. Jeftinija, and V. S.-Y. Lin, "A polyamidoamine dendrimer-capped mesoporous silica nanosphere-based gene transfection reagent," Journal of the American Chemical Society, vol. 126, no. 41, pp. 13216-13217, 2004.

[9] I. Slowing, B. G. Trewyn, and V. S. Y. Lin, "Effect of surface functionalization of MCM-41-type mesoporous silica nanoparticles on the endocytosis by human cancer cells," Journal of the American Chemical Society, vol. 128, no. 46, pp. 14792-14793, 2006.

[10] X. Zhao, R. A. P. Bagwe, and W. Tan, "Development of organicdye-doped silica nanoparticles in a reverse microemulsion," Advanced Materials, vol. 16, no. 2, pp. 173-176, 2004.

[11] L. M. Rossi, L. Shi, F. H. Quina, and Z. Rosenzweig, "Stöber synthesis of monodispersed luminescent silica nanoparticles for bioanalytical assays," Langmuir, vol. 21, no. 10, pp. 4277-4280, 2005.

[12] S. Cousinie, L. Mauline, M. Gressier et al., "Bulk or surface grafted silylated $\mathrm{Ru}(\mathrm{II})$ complexes on silica as luminescent nanomaterials," New Journal of Chemistry, vol. 36, no. 6, pp. 1355-1367, 2012.

[13] H. L. Handl and R. J. Gillies, "Lanthanide-based luminescent assays for ligand-receptor interactions," Life Sciences, vol. 77, no. 4, pp. 361-371, 2005.

[14] D. Jin and J. A. Piper, "Time-gated luminescence microscopy allowing direct visual inspection of lanthanide-stained microorganisms in background-free condition," Analytical Chemistry, vol. 83, no. 6, pp. 2294-2300, 2011.

[15] L. Jiang, J. Wu, W. Guilan et al., "Development of a visible-lightsensitized europium complex for time-resolved fluorometric application," Analytical Chemistry, vol. 82, no. 6, pp. 2529-2535, 2010.

[16] R. Connally, D. Jin, and J. Piper, "High intensity solid-state UV source for time-gated luminescence microscopy," Cytometry Part A, vol. 69, no. 9, pp. 1020-1027, 2006.

[17] Y. Bretonniere, M. J. Cann, D. Parker, and R. Slater, "Ratiometric probes for hydrogencarbonate analysis in intracellular or extracellular environments using europium luminescence," Chemical Communications, no. 17, pp. 1930-1931, 2002.

[18] J. Yu, D. Parker, R. Pal, R. A. Poole, and M. J. Cann, "A europium complex that selectively stains nucleoli of cells," Journal of the American Chemical Society, vol. 128, no. 7, pp. 2294-2299, 2006.
[19] R. Pal and D. Parker, "A single component ratiometric $\mathrm{pH}$ probe with long wavelength excitation of europium emission," Chemical Communications, no. 5, pp. 474-476, 2007.

[20] M. H. V. Werts, M. A. Duin, J. W. Hofstraat, and J. W. Verhoeven, "Bathochromicity of Michler's ketone upon coordination with lanthanide(III) $\beta$-diketonates enables efficient sensitisation of $\mathrm{Eu}^{3+}$ for luminescence under visible light excitation," Chemical Communications, no. 9, pp. 799-800, 1999.

[21] C. Yang, L. M. Fu, Y. Wang et al., "a highly luminescent europium complex showing visible-light-sensitized red emission: direct observation of the singlet pathway," Angewandte Chemie, vol. 43, no. 38, pp. 5010-5013, 2004.

[22] S. M. Borisov and O. S. Wolfbeis, "Temperature-sensitive europium(III) probes and their use for simultaneous luminescent sensing of temperature and oxygen," Analytical Chemistry, vol. 78, no. 14, pp. 5094-5101, 2006.

[23] J. Wu, Z. Ye, G. Wang et al., "Visible-light-sensitized highly luminescent europium nanoparticles: preparation and application for time-gated luminescence bioimaging," Journal of Materials Chemistry, vol. 19, no. 9, pp. 1258-1264, 2009.

[24] S. V. Eliseeva, B. Song, C. D. B. Vandevyver, A.-S. Chauvin, J. B. Wacker, and J.-C. G. Bünzli, "Increasing the efficiency of lanthanide luminescent bioprobes: bioconjugated silica nanoparticles as markers for cancerous cells," New Journal of Chemistry, vol. 34, no. 12, pp. 2915-2921, 2010.

[25] M. J. Li, Z. Chen, V. W. W. Yam, and Y. Zu, "Multifunctional ruthenium(II) polypyridine complex-based core-shell magnetic silica nanocomposites: magnetism, luminescence, and electrochemiluminescence," ACS Nano, vol. 2, no. 5, pp. 905912, 2008.

[26] H. R. Li, J. Lin, H. J. Zhang, L. S. Fu, Q. G. Meng, and S. B. Wang, "Preparation and luminescence properties of hybrid materials containing europium(III) complexes covalently bonded to a silica matrix," Chemistry of Materials, vol. 14, no. 9, pp. 36513655, 2002.

[27] L. A. Rocha, J. M. A. Caiut, Y. Messaddeq et al., "Non-leachable highly luminescent ordered mesoporous $\mathrm{SiO}_{2}$ spherical particles," Nanotechnology, vol. 21, no. 15, Article ID 155603, 2010.

[28] J. P. Duan, P. P. Dun, and C. H. Cheng, "Europium complexes having an aminophenanthroline ligand as red dopants in electroluminescent devices," AZojomo, vol. 1, 2005.

[29] J. K. F. B. Machado, A. L. Marçal, O. J. Lima, K. J. Ciuffi, E. J. Nassar, and P. S. Caleffi, "Materiais híbridos orgânicoinorgânicos (ormosil) obtidos por sol-gel com potencial uso como filtro solar," Química Nova, vol. 34, no. 6, pp. 945-949, 2011.

[30] E. De Oliveira, C. R. Neri, O. A. Serra, and A. G. S. Padro, "Antenna effect in highly luminescent $\mathrm{Eu}_{3+}$ anchored in hexagonal mesoporous silica," Chemistry of Materials, vol. 19, no. 22, pp. 5437-5442, 2007.

[31] L. R. Melby, N. J. Rose, E. Abramson, and J. C. Caris, "Synthesis and fluorescence of some trivalent lanthanide complexes," Journal of the American Chemical Society, vol. 86, no. 23, pp. 5117-5125, 1964.

[32] J. L. Yuan and K. Matsumoto, "A new tetradentate $\beta$ diketonate-europium chelate that can be covalently bound to proteins for time-resolved fluoroimmunoassay," Analytical Chemistry, vol. 70, no. 3, pp. 596-601, 1998.

[33] T. Mosmann, "Rapid colorimetric assay for cellular growth and survival: application to proliferation and cytotoxicity assays," Journal of Immunological Methods, vol. 65, no. 1-2, pp. 55-63, 1983. 
[34] B. R. Brinkley, P. T. Beall, and L. J. Wible, "Variations in cell form and cytoskeleton in human breast carcinoma cells in vitro," Cancer Research, vol. 40, no. 9, pp. 3118-3129, 1980.

[35] Q. He, J. Zhang, J. Shi et al., "The effect of PEGylation of mesoporous silica nanoparticles on nonspecific binding of serum proteins and cellular responses," Biomaterials, vol. 31, no. 6, pp. 1085-1092, 2010.

[36] D. A. Sheppard, C. F. Maitland, and C. E. Buckley, "Preliminary results of hydrogen adsorption and SAXS modelling of mesoporous silica: MCM-41," Journal of Alloys and Compounds, vol. 404-406, pp. 405-408, 2005. 

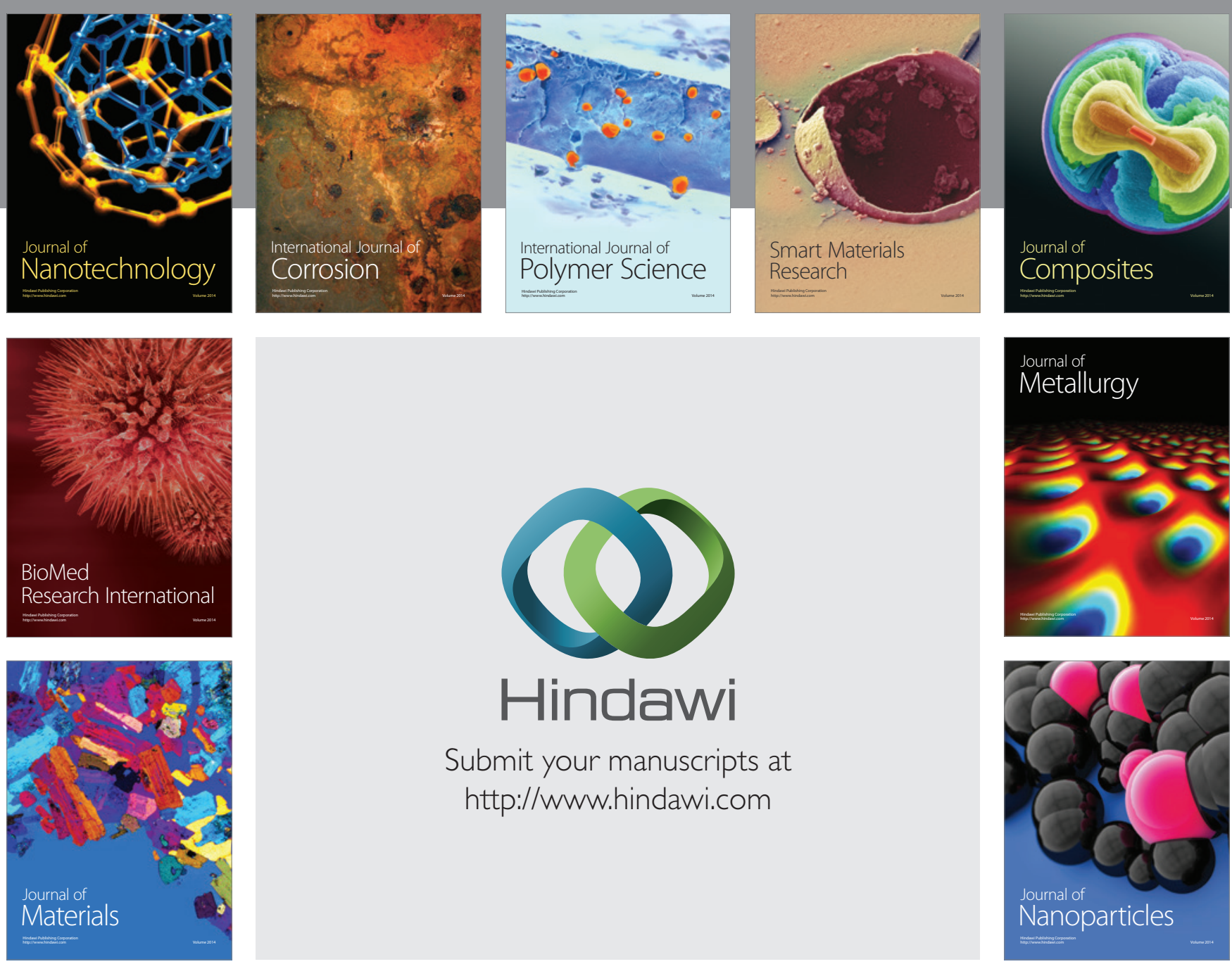

Submit your manuscripts at http://www.hindawi.com
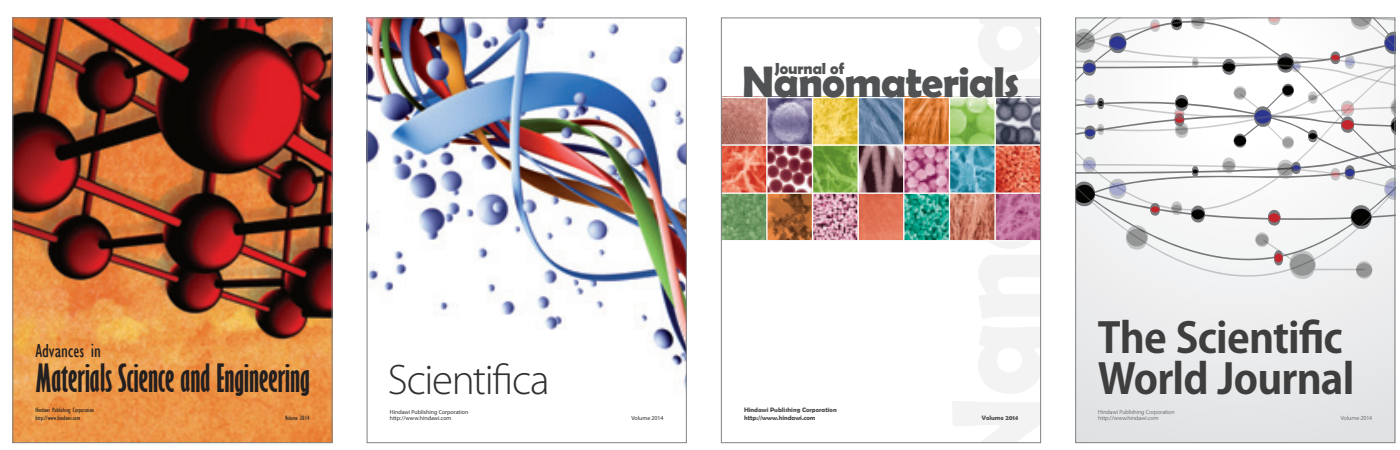

\section{The Scientific World Journal}
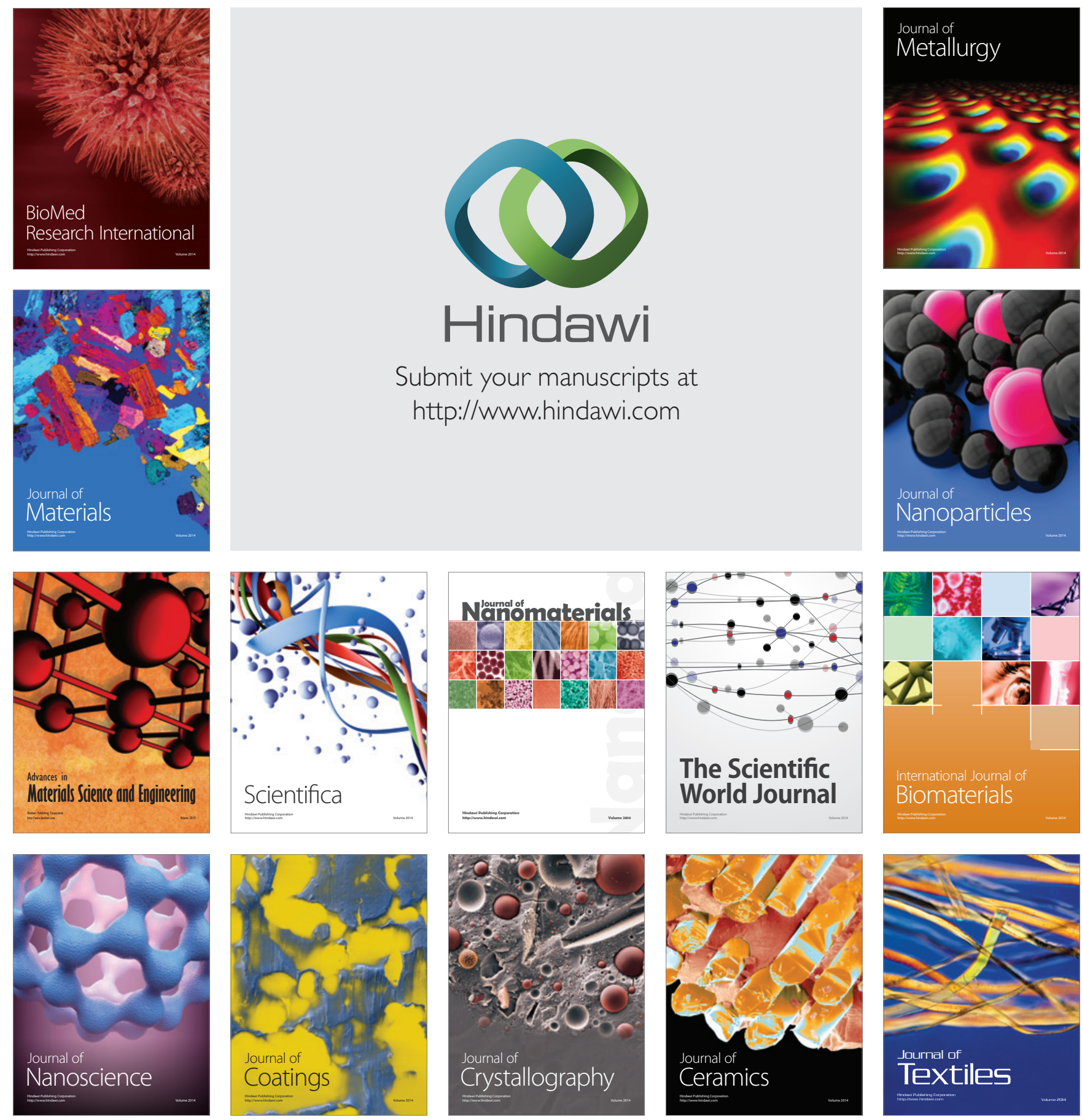